DOI: https://doi.org/10.32870/

eees.v21i60.287

Ignacio Medina Núñez

\title{
Política, democracia y liberalismo en el origen de la época moderna
}

En este artículo se enfoca la etapa del surgimiento de la modernidad desde los aportes del pensamiento político. Los debates proporcionados por los clásicos de los siglos XVI y XVII resuenan todavía

En este artículo se repasan los principales autores de teoría política de los siglos XVI y XVII. Se busca mostrar y reinterpretar sus aportaciones por la importancia que tienen para el análisis de los problemas del mundo contemporáneo. Se pretende que la política recobre su sentido original, aquel en que se entiende que el interés común debe predominar sobre el interés particular; aquel donde los gobernantes $y$ legisladores son un producto del pacto social que ha convenido un pueblo que debe permanecer soberano y poderoso. El propósito es mostrar cómo la teoría política renació en el inicio de la modernidad con varias corrientes ideológicas: la concepción de un Estado autoritario y soberano, el renacer del pensamiento democrático a través de la soberanía popular y del modelo de la democracia racional como forma superior de gobierno, y la propuesta de la primera separación de poderes del Estado con la creación del concepto liberalismo.

Palabras clave: política, democracia, liberalismo, modernidad.

- Profesor-investigador titular C, adscrito al Departamento de Estudios Ibéricos y Latinoamericanos de la Universidad de Guadalajara. Miembro del Sistema Nacional de Investigadores, nivel ॥

medina48@yahoo.com y son de gran importancia para el mundo contemporáneo toda vez que queremos rescatar el sentido original de la política, aquel que está basado en el interés común, aquel en que los gobernantes y los legisladores son producto totalmente de un pacto social. El renacer de la teoría política y los temas del liberalismo, la democracia y la participación ciudadana parte de un principio ideológico en las sociedades modernas y sus proyectos de nación, los cuales todavía están por construirse. Por eso, el estudio de estos pensadores clásicos contribuye a una cultura política democrática, pues nos recuerda el significado original de la palabra política, así como la obligación de los gobernantes por servir a sus comunidades.

Espiral, Estudios sobre Estado y Sociedad

Vol. XXI No. 60 \ayo / Agosto de 2014 
Surgimiento de la época moderna y la política en el siglo XVI

El origen de la época moderna se remonta al siglo XVI en Europa, aunque hay que entender que este fue un proceso prolongado; ${ }^{1}$ fue un gran cambio social en el contexto del surgimiento del modo de producción capitalista; momento cuando renacieron las ciencias naturales (Copérnico, Kepler y Galileo) con repercusión en todas las esferas del conocimiento. El estudio de la política también se empezó a diferenciar de la filosofía y de la teología para constituir una rama particular del pensamiento con escritos como los de Maquiavelo, Bodin, Hooker y Giordano Bruno, entre otros, durante el siglo XVI, cuyo contexto es la reforma protestante, el gran movimiento social frente al absolutismo de la jerarquía eclesiástica.

Sin embargo, durante el siglo XVII fue que se profundizaron las tendencias racionales del pensamiento político. Aunque el Renacimiento haya comenzado en el siglo XVI, "con Descartes (1596-1650) se inicia definitivamente la filosofía moderna" (Hirschberger, 1988: 163), puesto que con su obra se consolidó el racionalismo, una corriente que "significa literalmente filosofía de la razón. En concreto quiere decir que se trabaja preferentemente con la razón o con la inteligencia (en un principio, ambas cosas son lo mismo), con el pensamiento y con conceptos" (Hirschberger, 1988: 162). En el siglo XVII empezaron a brillar Francisco Suárez (1548-1617), Johannes Althusius (1557-1638), Hugo Grocio (1583-1645) y Spinoza (1632-1677), quienes empezaron a utilizar la razón para el análisis político de las sociedades

I. Como antecedente antes del siglo XVI se pueden mencionar a pensadores escolásticos que utilizaron constantemente la razón, como Tomás de Aquino, William de Ockham, John Duns Scoto (Doctor Subtilis), pero, sobre todo, Marsilio de Padua. Con todo, en la mayoría de ellos predomina la subordinación de la razón a los postulados de la fe.

\section{6}


Política, democracia y liberalismo en el origen de la época moderna

humanas. El siglo culminó con la propuesta del liberalismo político de John Locke (1632-1704), cuya obra sigue inspirando tanto los modelos de las sociedades modernas.

El surgimiento del nuevo pensamiento político de la modernidad surgió a partir de los textos de Maquiavelo ${ }^{2}$ Discursos sobre la primera década de Tito Livio, El Príncipe, Sobre el arte de la guerra. Por un lado, existe en el autor un acercamiento al modelo de la República romana, pero, por otro lado, sus obras son un acercamiento a la concepción práctica del poder en la sociedad, donde nada tiene que ver la interpretación teológica: la sociedad se mueve por sí misma a partir de la habilidad o fuerza de los gobernantes, aunque, claro, queda siempre un considerable margen al obrar de la fortuna o la suerte.

Dentro de la conformación de los Estados nacionales surgió también la propuesta de la laicidad del gobierno a partir del postulado fundamental de la tolerancia religiosa. Con la represión contra las reformas promovidas por Martín Lutero en el siglo XVI, a pesar de profesar la fe en el mismo Jesucristo, los protestantes fueron perseguidos y excomulgados. De este tiempo datan las sangrientas guerras religiosas entre católicos y protestantes, con la experiencia de uno de los hechos más sangrientos de la historia, la noche de San Bartolomé en la Francia de 1572. Libertad de creencias y tolerancia religiosa empezaron a ser demandas fundamentales de la primera teoría política moderna.

La experiencia de la política de la Iglesia católica en el siglo XVI, y particularmente el seguimiento de la vida de Cesare Borgia -segundo hijo natural de Rodrigo Borgia, el papa Alejandro VI-, fue lo que motivó a Maquiavelo a

2. Existen otros textos de Maquiavelo que no han sido tan conocidos pero que también ayudarían a entender su pensamiento sobre la sociedad, una vez que fue obligado a dejar los puestos públicos: Ordenanza de la Infantería, Ordenanza de la Caballería, Discurso sobre la Lengua, Discurso Moral, Historias Florentinas, Vida de Castruccio Castracani, y la satírica obra de teatro La Mandrágora.

Teoría y DEBATE No. 60 
escribir El Príncipe (De Principatibus). La biografía de toda la familia Borgia es una muestra de cómo se disputaba el poder real en ese tiempo. César Borgia fue Obispo de Pamplona a los 16 años, arzobispo de Valencia a los 19 y capitán general del Vaticano y cardenal a los 20; sin embargo, renunció a la vida eclesiástica y se dedicó luego a la carrera militar, para morir en una batalla en 1507, a los 31 años de edad. El ascenso político de César se había detenido con la muerte de su máximo protector, el papa Alejandro $\mathrm{VI}^{3}$ en 1503 y por ello señaló luego Maquiavelo que el destino de un político poderoso no solamente depende de sus habilidades como príncipe, sino también de la fortuna o de la suerte. El hecho es que el siguiente papa, Julio II (1503-1513), con tres hijas ilegítimas y una gran fortuna, con poco interés por la misión espiritual de la Iglesia y más con la ambición de ser un poderoso gobernante, fue totalmente contrario al hijo de Alejandro VI, de quien había sido enemigo personal. Julio II fue quien colocó la primera piedra para la construcción de la Basílica de San Pedro en el Vaticano y su principal preocupación fue la expansión de los Estados pontificios. Bajo su pontificado surgió la iniciativa de propagar la doctrina de las indulgencias en todos los lugares de Europa con el objetivo de conseguir mayor financiamiento para la construcción de la Basílica. En 1513 ascendió un nuevo papa, León X (15131521), quien logró consolidar el papado como la fuerza más poderosa de Italia; se encargó de proseguir la consecución de financiamiento para las construcciones en Roma a través de las indulgencias ${ }^{4}$ y tuvo que enfrentar la reacción pública

3. Se dice que este papa se deshacía de sus enemigos envenenándolos. Un historiador señala que "Alejandro [...] se propuso una vez eliminar por medio del veneno a uno de los cardenales más ricos, quien pudo sobornar con regalos, promesas y ruegos al jefe de cocina del papa. La pócima destinada al cardenal fue ofrecida al papa y así murió del veneno que él había preparado para otro" (Ranke, 2000: 34).

4. Hubo casos extremos, por ejemplo, cuando el papa autorizó al arzobispo Albrecht de Mainz, en I52I, la exhibición de 9000 reliquias en el monasterio

\section{8}


Política, democracia y liberalismo en el origen de la época moderna

de protesta de Martín Lutero, cuando este proclamó públicamente en Alemania sus 91 tesis en 1517. León X murió en 1521, no sin excomulgar a Lutero el año anterior.

Después de Adriano VI y su breve pontificado, la designación del siguiente papa cayó en Clemente VII (1523-34), quien vivió la separación de Inglaterra de la Iglesia católica, cuando el rey Enrique VIII se quiso divorciar de su esposa Catalina de Aragón para casarse con Ana Bolena; algo que el sumo pontífice nunca quiso autorizar al soberano y, en su lugar, lo excomulgó. Enrique VIII ordenó la separación oficial con el papado, volviendo su mirada a la Iglesia anglicana y apoderándose de todos los bienes de los católicos en Inglaterra. La boda real de Enrique VIII con Ana Bolena en 1535 sirvió de ocasión para la ejecución de Thomas More, quien había sido canciller de Inglaterra y amigo personal del rey, pero que nunca quiso avalar ni el divorcio ni las nuevas nupcias del monarca. La figura de More resalta todavía en el ámbito de las ciencias sociales porque su obra Utopía (De optimo reipublicae statu deque nova insula utopia), escrito en 1516, propone un modelo imaginado de gobierno, que inspirado en relatos venidos del Nuevo Mundo, es un antecedente para vislumbrar la perspectiva de sociedades mejores.

El contraste entre la política real señalada por Maquiavelo y el ideal de Utopía propuesto por Thomas More se convertirá en un debate constante sobre el ser y el deber ser de la política y de cualquier gobierno: hay quienes preferirán adaptarse a la realidad de la política, con su eterna lucha por el poder utilizando cualquier medio, y hay quienes, a partir

de Halle que consistían en partes del cuerpo de muchos santos y cuarenta y dos cuerpos completos de ellos, con los cuales uno podría ganar hasta treinta y nueve millones de años de ahorro en el purgatorio; "las reliquias incluían un pedazo de barro con el que Dios había hecho a Adán, una parte del arbusto ardiente que Moisés había visto en la montaña, algunos vasos que contenían leche de la Virgen María, y el dedo que Tomás había colocado en el costado de Jesús resucitado" (Marius, 1999: 320).

Teoría y DEBATE No. 60 
de la existencia de los conflictos reales, pondrán siempre su esfuerzo para que prevalezca el interés colectivo sobre los particulares. El tema de la utopía como algo inexistente en el mundo real (ои́топía: sin lugar) pero como algo a lo que se puede aspirar, un sueño que podría convertirse en realidad, tiene sus raíces en la misma filosofía política, en la visión

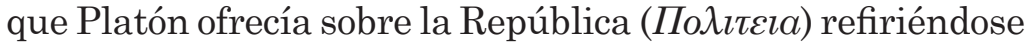
al modelo ideal de sociedad en donde los filósofos gobernantes pueden ser los guías que conduzcan a los hombres. Sin embargo, es a partir de Utopía de Thomas More que se empezó a entender y extender en las ciencias sociales modernas el planteamiento del poder de la imaginación ${ }^{5}$ sobre los modelos deseables de sociedad, no como un factor de alienación y fuga de la realidad, sino fundamentalmente como un motor de cambio en la subjetividad de los actores y en los movimientos sociales.

De manera opuesta, El Príncipe de Maquiavelo exponía la vida real del siglo XVI y sus conflictos de poder, así como la manera de resolverlos; no importaba el sentido público y colectivo de la política, sino las habilidades para conseguir poder, mantenerse en él y aumentarlo. Se trata de un escrito sobre la habilidad política de quienes ejercen algún tipo de poder, donde no hay lugar para la moral o la ética, porque se trata de mantener el poder mediante la fuerza y la astucia. Maquiavelo, acompañando la vida política-militar de César Borgia, hablaba de una experiencia práctica; él mismo contribuyó a reorganizar las defensas militares de Florencia. No obstante, cuando la familia Medici en Italia fue recobrando el poder -especialmente en la misma Flo-

5. Una excelente visón histórica de la utopía planetaria nos la ofreció Armand Mattelart (2000) refiriendo numerosas concepciones de este tipo de pensamiento desde el siglo XVI hasta el siglo $\mathrm{Xx}$.Y desde otras perspectivas muy sugerentes e iluminadoras tenemos los planteamientos de Gaston Bachelard en varias obras (La Terre et les rêveries de la volonté; Le droit de rêver; La Poétique de la rêverie; L'Eau et les rêves; L'air et les Songesk) y los aportes de René Barbier (2007), Cornelius Castoriadis (1996) y Gilberto Giménez (1976). 
Política, democracia y liberalismo en el origen de la época moderna

rencia en el año 1512- Maquiavelo perdió todos sus cargos y fue encarcelado por un tiempo. Puesto en libertad, permaneció en los alrededores de Florencia hasta su muerte en 1527, dedicándose a escribir sus obras. Con su tesis de El Príncipe el autor no pretende defender el despotismo ${ }^{6}$ o la tiranía, sino simplemente dar cuenta del modo real como se disputa el poder y, por ello, al partir de los fenómenos reales de la sociedad, es considerado por muchos autores como el primer antecedente de la ciencia política moderna:

El discurso maquiaveliano se halla entre dos épocas, a tal punto que los mismos términos que emplea a menudo parecen haber abandonado toda claridad consolidada, sin haber alcanzado todavía la especificación conceptual que será característica del discurso político de la modernidad [...]. La doctrina de Maquiavelo posee entonces al mismo tiempo un carácter preliminar y excéntrico. Por un lado, representa un lugar de paso desde la consideración medieval a la moderna sobre las tareas del príncipe y el poder monárquico, por el otro, una alternativa y una interrupción en la comprensión práctica del régimen republicano (Ricciandi Maurizzio; en Duso, 2005: 30).

Habría que mencionar también para esta época los aportes de Erasmo ${ }^{7}$ de Rotterdam (1466-1536), Richard Hooker

6. Aunque con bastante fundamento Maquiavelo puede ser ubicado en el mundo del pragmatismo político, hay que tener en cuenta ciertos postulados implícitos o explícitos que van a coincidir con planteamientos clásicos de la modernidad: por primera vez empieza a separar el orden político del religioso, algo todavía inconcebible en su tiempo cuando se postulaba que todo poder emana de Dios; por otro lado, en los Discursos sobre la primera década de Tito Livio muestra con mucha claridad su admiración por el modelo de la república romana, como algo que es superior a las debilidades de la monarquía absoluta. Incluso en el propio texto de El Príncipe es posible concluir que las cualidades del gobernante no están enfocadas a la obtención del poder personal, sino a la seguridad y bienestar del naciente Estado nación frente a los enemigos.

7. Sus obras más importantes son los Adagios (Adagiorum Chiliades), el Manual del Caballero Cristiano (Enchiridion militiis christiani), el Elogio de la Locura (Enchomion moriae seu laus stultitiae), Sobre el método del Estudio (De ratione studii), Educación del príncipe cristiano (Institutio principis christiani), La Enseñanza firme pero afable 
Ignacio Medina Núñez

(1574-1600), Giordano Bruno ${ }^{8}$ y Jean Bodin (1530-1596). Este último comenzó a teorizar la política a partir del uso de la razón; analizó cómo las fuerzas irracionales tales como la intolerancia religiosa, la corrupción, los intereses particulares, etc., pueden controlar el mundo de la política y derrumbar el Estado. Expresaba un postulado fundamental señalando que el espíritu colectivo es el que debe regir el comportamiento político, pero poniendo la soberanía en el monarca a la cabeza del Estado. Se ha mencionado que Bodin "fue casi el único pensador del siglo XVI en hacer un intento serio por construir una teoría global de la sociedad política" (UNAM, 1988: 35). Sin embargo, tampoco hay que suponer que en Bodin existe un despotismo absoluto del monarca, porque también en algún momento llegó a señalar la existencia de ciertos contrapesos legales ${ }^{9}$ cuyo fin es evitar la tiranía.

\footnotetext{
con los Niños (De pueris statim ac liberaliter instituendis), Coloquios, Disquisición cerca del Libre Albedrío (De libero arbitrio diatribe), dos tomos sobre Hyperaspistes (una réplica al texto de Lutero $D e$ servo arbitrio).

8. Giordano Bruno (1548-1600) murió en la hoguera como fruto de la intolerancia de la Iglesia católica materializada en la Inquisición, especialmente a partir de sus postulados de entusiasmo y amor por el cosmos infinito que provocaron la acusación de panteísmo. Toda la pasión, interés y entusiasmo que la Edad Media tenía por la otra vida, Bruno la vierte sobre el hombre y el mundo presente a través de un inmanentismo que fue calificado de panteísmo, pero él permaneció fiel a sus concepciones hasta soportar la muerte, acusado de blasfemia, herejía e inmoralidad.

9. Aunque se habla constantemente del absolutismo de los reyes al término de la Edad Media, desde antes del nacimiento de la época moderna se pueden encontrar diversos intentos de contrapeso a la autoridad del Rey. En Inglaterra, por ejemplo, la guerra militar entre el rey Carlos I y las fuerzas del parlamento mostraron ya con claridad en el siglo XVII (guerra de 1640-1648) la total confrontación entre bandos que terminó con el triunfo de la nobleza, de cuyo proceso surgió después la Glorious Revolution de 1688 con el modelo de la moderna monarquía parlamentaria; sin embargo, en la misma Inglaterra existe el antecedente de la guerra de los Barones contra el King John Lackland, el llamado Juan sin Tierra, en 1215, en donde nació la Magna Carta, que después fue modificándose en Carta libertatum en 1216 y otra sucesivas versiones, en donde siempre se demandaban peticiones de la nobleza con acuerdos para limitar el poder absoluto del monarca.
} 
Política, democracia y liberalismo en el origen de la época moderna

Particularmente hay que enfatizar la postura de un Estado ante la intolerancia religiosa, porque Bodin vivió los sucesos de la guerra sangrienta entre hugonotes (protestantes franceses influenciados por Calvino) y católicos, cuya expresión más terrible fue la llamada Noche de San Bartolomé (24 de agosto de 1572), cuando fueron degollados más de 10 mil protestantes solamente en París, y más de esa cantidad en el resto de Francia. El mismo Bodin se opuso posteriormente a la supresión legal de los hugonotes -porque las matanzas proseguían-, por lo cual cayó de la gracia de los monarcas franceses. Después de la experiencia de aquella noche, escribió, y apareció en 1576 su libro sobre la república, con el cual postuló la separación de la Iglesia y el Estado, aunque siempre fundamentándose en la soberanía del poder gobernante.

Teoría política y democracia en el siglo XVII

En el siglo XVII, en el ámbito político, comenzó la expresión de una teoría más sistemática con los aportes de Suárez, Althusius, Hugo Grotio, Hobbes, Spinoza y Locke. Se empezó a recuperar de manera explícita el concepto democracia, primero con Francisco Suárez con su De Legibus ac Deo Legislatore y posteriormente con Spinoza a través de su Tractatus Theologico-Politicus.

De hecho, el pensamiento de Suárez (1548-1617) llamado Doctor Eximius reflejaba la transición de un siglo a otro, queriendo volver a los autores griegos y latinos pero enfatizando el concepto de soberanía popular. En relación con lo político y social encontramos un gran aporte que rebasa, sobre todo en el nivel sistemático, lo que ya habíamos encontrado en el siglo XVI, con repercusiones para el debate contemporáneo: "La actualidad del pensamiento de Suárez se debe no sólo a que se le considera uno de los padres de la democracia moderna, del derecho internacional y de la

Teoría y DEBATE $\&$ No. 60 
legítima secularización de lo político, sino también a lo que puede aportarnos hoy su comprensión de la relación entre lo político y lo social" (Scanone, 1998: 131). Se trata de novedades muy significativas sobre la concepción de la sociedad y las formas de gobierno en donde apareció con fuerza el tema de la soberanía del pueblo y el concepto de democracia y la necesidad de la ley.

En este campo, Suárez fue el mediador entre la concepción medieval de la ley, tal como la representaba el tomismo, y las condiciones dominantes en la época en que él escribía. A la luz de aquellas condiciones, elaboró una filosofía jurídica, y, en conexión con ésta, una teoría política que, por su alcance y por su carácter de totalidad, fue más allá de todo lo elaborado en la Edad Media, y que ejerció una influencia profunda (Copleston, 1988a: 362).

El punto de partida ${ }^{10}$ es el análisis de la ley como precepto justo tendiente a fortalecer el bien común distribuyendo cargas de una manera equitativa para toda una comunidad. Establecía al mismo tiempo la contraposición con una ley injusta que tendiente a propiciar ventajas para intereses privados, carecía de obligatoriedad para los ciudadanos. La necesidad de las leyes deriva de la naturaleza propia de los seres humanos atraída tanto al bien como al mal; por ello, son imprescindibles estos mandatos legales sobre toda la comunidad. Estos mandatos, en último término, proceden de una ley eterna, ${ }^{11}$ pero dentro de la naturaleza histórica

10. La fuente de las siguientes reflexiones se encuentran sobre todo en el texto De Legibus (16|2), pero también hay ideas extraídas de otros de sus textos como el De opere sex Dierum (publicación póstuma en I62I) y Defensio Fidei catholicae et apostolicae adversus Anglicanae sectae errores (16/3). En este último, el libro I se titula "Principatus politicus o la soberanía popular".

II. Suárez es un representante claro del iusnaturalismo, una concepción que viene desde los presocráticos a partir de una ley natural inmutable que debe determinar las acciones humanas y que incluye principios que son universales y anteriores a todo tipo de ordenamiento jurídico. El iusnaturalismo decayó en el siglo XIX cuando ya solamente era defendido por ciertas corrientes católicas. En el siglo 
Política, democracia y liberalismo en el origen de la época moderna

de las comunidades humanas, tienen que tener su origen en una autoridad humana legítima.

Aparte de distinguir la ley natural (como principios universales) de la ley civil (mandatos escritos para los súbditos de un Estado), Suárez ofrecía su concepto del ius gentium -con su origen también en Tomás de Aquino- con el objeto de propiciar la convivencia pacífica. La base racional del ius gentium es la concepción de que, a pesar de los límites de los Estados, los seres humanos provienen de una misma especie en donde su comportamiento moral y político puede tener bases únicas. Esta concepción de Suárez y las reflexiones que hace sobre la guerra entre las naciones serán conocidas por Hugo Grotio para formular varias décadas después en su obra De Iure Belli ac Pacis lo que muchos han llamado los primeros principios de las relaciones internacionales.

Retomando el principio establecido por Aristóteles sobre el hombre como animal político, Suárez se refiere en el libro tercero de la obra De Legibus a la ley humana positiva. Se pregunta quién hace las leyes para la comunidad política: se necesita un gobierno como poder gobernante. En este momento, Suárez se separa radicalmente del pensamiento de Jean Bodin -quien había puesto la soberanía en el gobernante- señalando que la naturaleza no ha conferido a ningún hombre superioridad sobre otro; la soberanía es de todos.

Las comunidades políticas se han constituido a través de un consentimiento explícito y por ello el poder de hacer leyes reside fundamentalmente en ellas aunque su origen sea divino en último término. Dios es la causa primera de todo pero la misma naturaleza humana produce la necesidad de vivir en la polis como causa segunda, y esto es lo que determina la forma de una comunidad de vida a través de

XX, por ejemplo, el llamado Círculo de Viena rechazó todo tipo de metafísica para abocarse a un neopositivismo en donde el pensamiento científico debería depender solamente de tesis verificables. 
un consenso: "la modernidad de Suárez se muestra en su acentuación de la libertad y, por eso, de la necesidad del consenso voluntario" (Scanone, 1998: 134). Encontramos que el poder de hacer leyes radica esencialmente en la comunidad, en el pueblo (retomando conceptos ya utilizados siglos antes por Cicerón: populus o respublica). Sin embargo, como escribió Copleston (1988a: 376-7):

[...] sería extraordinariamente difícil que toda la comunidad como tal legislase directamente, y consideraciones prácticas apuntan a la monarquía como la mejor forma de gobierno, aunque por regla general es conveniente, dado el carácter del hombre añadir algún elemento de gobierno común. Cuál deba ser ese elemento de gobierno común depende de la elección y la prudencia humana. En todo caso, quien quiera que detente el poder civil, ese poder deriva, directa o indirectamente, del pueblo como comunidad. En caso contrario, no sería justamente detentado. Para que la soberanía pueda radicar justamente en un individuo determinado, tiene que ser asignada a éste por el consentimiento de la comunidad.

Existe un consenso para formar la comunidad política, y otro pacto entre la comunidad para designar a determinado gobernante. Si distinguimos la ley natural de las otras que guían el comportamiento de una comunidad, encontramos con claridad que las formas de gobierno no las determina la naturaleza sino la elección humana de las distintas comunidades. "Aunque ese poder sea de derecho natural en términos absolutos, su concreción en una forma determinada ( $a d$ certum modum postestatis et regiminis) depende de la libre decisión de los hombres" (Suárez; citado en Scanone, 1998: 149). La naturaleza dicta que el poder político pertenece a toda la comunidad, pero no siempre es posible establecer la forma de una democracia directa en la elaboración de todas las leyes, porque habría muchas complicaciones, confusiones y larga esperas de tiempo; de esta manera, los 
Política, democracia y liberalismo en el origen de la época moderna

seres humanos escogen alguna de las formas de gobierno conocidas (la monarquía, la aristocracia o la democracia representativa, o la mezcla de varias), según los pareceres y opiniones en cada momento histórico.

Resulta clara una concepción de la democracia como poder de la comunidad que tiene su origen natural, aunque exista la necesidad luego de delegar el poder en una forma monárquica, incorporando contrapesos con la participación de múltiples ciudadanos, porque la ignorancia y la malicia también se pueden apoderar de los gobernantes; hay que poner límites a la autoridad de los reyes; esos límites estarán dados siempre por el bien común y la propia ley natural. Retomando a Tomás de Aquino, este filósofo señala que una vez que el gobernante recibe el poder de la soberanía de parte de la comunidad, también puede abusar de él a través de decisiones y leyes injustas que lo convierten en tirano. En esta situación se retoma la misma postura de Aquino: el pueblo tiene derecho a una legítima defensa, e incluso tiene derecho a la rebelión con el objeto de defender sus intereses. En Suárez, encontramos el resurgimiento del poder del pueblo, de la comunidad, la cual es la verdadera depositaria de la soberanía y la que puede hacer oír su voz, desobedecer o incluso rebelarse frente al autoritarismo de un tirano. Otro asunto le trajo controversias con la misma Iglesia católica:

Suárez discute y rechaza la opinión de que el papa posee no solamente supremo poder espiritual sino también supremo poder civil, con la consecuencia de que ningún soberano puramente temporal posee poder supremo en asuntos temporales. Suárez apela a declaraciones de papas, y luego procede a argumentar que no puede descubrirse justo título alguno por el que el papa posea jurisdicción directa sobre todos los Estados cristianos en los asuntos temporales. $Y$, sin un justo título, no puede poseer tal jurisdicción. No hay pruebas de que ni la ley divina ni la humana se la hayan conferido. Suárez reconocía, desde luego, la

Teoría y DEBATE $\&$ No. 60 
jurisdicción temporal del papa como gobernante temporal sobre los Estados Pontificios; pero se negaba a considerar a los otros soberanos temporales como meros vicarios de la Santa Sede. En otras palabras, Iglesia y Estado son sociedades distintas e independientes (Copleston, 1988a: 382-3).

Se anuncia aquí el principio de la separación de Iglesia y Estado. Aunque Suárez suavizaba su posición reconociéndole al papa una jurisdicción espiritual, nada le valió frente a la intolerancia: la Iglesia católica no recibió bien sus ideas y él recibió severos ataques tanto en España como en Roma y, por otro lado, por ejemplo, su Defensio Fidei fue quemado por orden del rey James I en el patio del parlamento inglés; algo que más tarde también ocurrió en París. Hay que entender que sus posturas se refieren a los derechos inalienables del pueblo frente al despotismo de los gobernantes, adelantando ya una posición clara sobre un futuro Estado democrático. Con toda razón se puede calificar a Suárez como el padre de la democracia moderna.

Casi de manera contemporánea con Suárez e intentando un claro rigor metodológico en el campo de la política, encontramos en el mismo tránsito del siglo XVI al XVII a Joannes Althusius ${ }^{12}$ (1557-1638), proveniente del mundo protestante del calvinismo, particularmente con su obra Politica methodice digesta, et exemplis sacris atque profanis illustrata, publicada en 1603, intentando, como lo expresa el título, examinar la política de una manera metódica. Su énfasis se encuentra en defender también la soberanía popu-

12. El aporte del pensamiento de Althusius no encontró eco por varios siglos debido al poder ideológico de los defensores de la autoridad de los monarcas; sin embargo, el alemán Otto Friedrich von Gierke lo rescató en I 880 con su gran obra Johannes Althusius und die Entwicklung der naturrechtlichen Staatstheorien. Nadie duda actualmente de sus grandes aportaciones en el inicio de la modernidad y para difundir su pensamiento se ha creado y funciona actualmente la JohannesAlthusius-Gesellschaft en la dirección www.althusius.de/ 
Política, democracia y liberalismo en el origen de la época moderna

lar del Estado a través de un contrato entre los miembros simbióticos (simbiotici) de una comunidad.

Althusius menciona el acuerdo de los seres humanos para formar una asociación guiada por el bien común, el cual se manifiesta en leyes generales. El término simbióticos (symbiotici) es utilizado por el autor de manera frecuente para indicar la necesaria vida en común de todos los miembros de la comunidad. También menciona un segundo tipo de contrato social cuando la comunidad decide tener una autoridad con funcionarios administrativos a quiénes delegar la soberanía, cuyo origen sigue estando en el pueblo. Además, siempre existe el derecho a la resistencia frente al tirano, un derecho a la rebelión cuando dichas autoridades dejan de servir al bien común para el que fueron creadas. En este sentido, al igual que Suárez, pero a diferencia de Jean Bodin y de Hugo Grotius, ${ }^{13}$ Althusius es también representante del concepto soberanía popular del Estado moderno, contrario a las tesis absolutistas de la época feudal en que se entendía el poder de los reyes como concedido directamente por Dios. Sin embargo, este autor también añade al estudio de la política el concepto expreso del federalismo moderno, en donde el Estado está compuesto por organismos menores que pueden ser las entidades económicas, las ciudades o regiones, que guardan una autonomía relativa en relación con el poder central de la nación.

La Política de Althusius fue el primer libro en presentar una teoría comprensiva del republicanismo federal, nacido desde la perspectiva de

13. Años más tarde, Hugo Grotius (1583-1645) en sus principales obras (Mare Liberum, De iure belli ac pacis; De iure naturae et gentium) presenta uno de los primeros aportes para regular las relaciones internacionales, pero él mismo contradecía a Althusius en la tesis de que la soberanía reside siempre y esencialmente en la comunidad política como asociación de hombres libres, porque el pueblo puede transferir la soberanía al designar a un gobernante; de esta manera, el pueblo retiene unos derechos pero transfiere otros al rey; se trata en su concepción de una soberanía dividida.

Teoría y DEBATE No. 60 
Ignacio Medina Núñez

un convenio de la sociedad humana y derivado, aunque no dependiente, de un sistema teológico. Se presentaba una teoría sobre la construcción de una comunidad social como una asociación política establecida por los ciudadanos desde abajo sobre la base de un consenso más que sobre un estado impuesto por el gobernante o por la élite (Elazar, 2010).

La estructura del Estado tiene como poder manifiesto en la punta al príncipe o magistrado supremo, pero su soberanía viene desde abajo, de la comunidad de los ciudadanos o simbióticos; teniendo en cuenta a las ciudades o regiones. Estas tienen a sus propios magistrados autónomos, los cuales -recordando a los príncipes electores (Kurfürsten) del sacro Imperio germánico (Sacrum Romanum Imperium) o a los éforos de la antigua Esparta- son representantes elegidos por los ciudadanos de las provincias federadas y sirven también de consejeros y de contrapeso a la autoridad central ${ }^{14}$ para evitar cualquier tipo de despotismo o desviación del bien común.

Concedo que el príncipe o magistrado supremo es el guía, administrador y supervisor de todos los derechos. Pero yo mantengo que la propiedad de ellos y el usufructo pertenece propiamente a todo el conjunto o al pueblo... La administración de los derechos se le ha otorgado al príncipe a través de un convenio pero cuando éste muere, ellos retornan al pueblo, quien en realidad a través de una perpetua sucesión es inmortal. Esta administración le es confiada por el pueblo a otro, que puede ser una o más personas. Pero el propietario y usufructuario de estos derechos no puede permanecer en nadie más que en el pueblo en su totalidad (Althusius, 1964).

14. La influencia del protestantismo también es notoria en esta postura puesto que se recuerda la posición de los reformistas de resistir a la autoridad central pontificia debido al poder divino que tienen los creyentes dentro de las comunidades locales y regionales, que también eligen a sus representantes. Semejante oposición a la suprema autoridad de la Iglesia de Roma fue la que había provocado en 1054 el Gran Cisma de Oriente de la iglesia cristiana griega. 
Política, democracia y liberalismo en el origen de la época moderna

En este sentido, las dos principales aportaciones del Althusius para el pensamiento moderno se encuentran en la soberanía popular, por un lado, y luego en el concepto federalismo en los Estados. Hay que notar que, a diferencia de Suárez, quien vivió toda su vida en el estudio y la enseñanza, Althusius participó directamente en responsabilidades políticas cuando la ciudad de Emden (Frisia del este, hoy dentro de Alemania) lo eligió en 1604 como síndico municipal (Ratssyndikus), jefe administrativo y responsable jurídico, un cargo que ejerció hasta su muerte en 1638, en donde tuvo que poner en operación gran parte de su teoría. En el capítulo primero de su obra, titulado "De generalibus politicae", define con claridad su objeto de estudio:

La política es el arte mediante el cual los hombres se asocian con el propósito de constituir, cultivar y conservar la vida social entre ellos. Por eso los llamo simbióticos. El principal sujeto de la política es, pues, la asociación, en la cual los simbiotes se comprometen entre ellos, uno con el otro, a través de un acuerdo explícito o tácito, para tener un tipo de comunicación sobre todo aquello que es útil y necesario para el ejercicio armonioso de la vida Social ${ }^{15}$ (Althusius, citado en Hueglin, 1999: 85).

La política es concebida como la consociatio symbiotica, cuya esencia es el interés común y la necesaria participación de todos los integrantes en la vida comunitaria. Los ciudadanos aparecen unidos por un contrato al cual debe subordinarse cualquier gobernante bajo cualquiera forma de gobierno. "Es la conceptualización de la política como un proceso permanente de construcción de la comunidad. El

15. El texto original dice de esta manera:"Politica est ars homines ad vitam socialem constituendam, colendam \& conservandam, consociandi. Unde $\sigma U \mu \beta I \omega T I K \eta$ vocatur. Proposita igitur Politicae est consociatio, qua pacto expresso, vel tacito, symbiotici inter se invicem ad communicationem mutuam ceorum, quae ad vitae socialis usum \& consortium sunt utilia \& necessaria, se obligant" (Hueglin, 1999: 85).

Teoría y DEBATE No. 60 
pacto puede ser explícito o tácito porque está basado en una renovación permanente implícita a través de un proceso de comunicación y construcción del consenso" (Hueglin, 1999: 86). Este es el significado de la política como un continuo proceso de consociatio ejercido a través de la comunicación de bienes, obras y derechos comunes.

Con otra posición, también hay que mencionar a Hobbes, quien partía ya no de la tendencia del hombre para vivir en sociedad y buscar el bien común, sino de un estado natural de guerra (competencia, desconfianza y vanagloria o deseo constante de fama), cuyo origen se encuentra en la misma esencia del hombre. Recordando un dicho de Tito Macio Plauto (254-184 a.C.) sobre cómo la vida del ser humano es un estado de guerra parecido al de los lobos debido a su propia naturaleza (Lupus est homo homini), Hobbes llegó a puntualizar cómo el hombre, abandonado a sus propias tendencias naturales, se parece a las fieras y acabaría destrozándose y destruyéndose si no existiera un pacto explícito de no agresión y, al mismo tiempo, un poder real con capacidad de fuerza para castigar y poder para garantizar el respeto del pacto. Dicho pacto no puede ser solamente de palabra, porque los acuerdos verbales son fácilmente rompibles: se necesita que surja el Leviathan -la leyenda de un monstruo marino de la antigüedad-, con su fuerza capaz de imponer reglas básicas de convivencia, incluso por medio de la violencia:

Los pactos que no descansan en la espada no son más que palabras, sin fuerza para proteger al hombre, en modo alguno. Por consiguiente, a pesar de las leyes de la naturaleza (que cada uno observa cuando tiene la voluntad de observarlas, cuando puede hacerlo de modo seguro), si no se ha instituido un poder o no es suficientemente grande para nuestra seguridad, cada uno fiará tan sólo, y podrá hacerlo legalmente, sobre su propia fuerza y maña, para protegerse contra los demás hombres (Hobbes, 1994: 137-8). 
Política, democracia y liberalismo en el origen de la época moderna

El Estado-nación moderno es ese Leviathan que se impone a toda la sociedad para que ella misma pueda subsistir; de otra manera, reinaría el caos y la guerra, debido a que todo ser humano se mueve llevado por sus intereses particulares. No se trata de ninguna dictadura, porque es un acuerdo manifiesto de transferencia de soberanía: los ciudadanos aceptan voluntariamente dicho pacto, pues saben lo necesaria que es la existencia de una entidad que pueda controlar los instintos individuales del ser humano, tendientes a la destrucción. Hay un pacto explícito interesado en una convivencia pacífica a partir de un latente estado de guerra. El respeto a la autoridad estatal se da por un impulso de preservación de la especie. "Esto es algo más que consentimiento o concordia; es una unidad real de todo ello en una y la misma persona, instituida por pacto de cada hombre con los demás"16 (Hobbes, 1994: 141); es el CIVITAS o el Leviatán. El Estado, entonces, es una institución política de fuerza fundada por el pacto de una gran multitud de individuos que se somete voluntariamente a ella debido a su estado natural de guerra. ${ }^{17}$ Como se ve, no existe en Hobbes ninguna alusión al poder divino de los reyes, porque no cree en él -ni siquiera en el del papa-; ${ }^{18}$

16. Así dice el texto original de Hobbes: "I authorize and give up my right of goberning myself to this man, or to this assembly of men, on this condition, that you give up our right to him and authorize all his actions in this manner.This done, the multitude so united in one person is called a Commonwealth, in Latin CIVITAS. This is the generation of the great LEVIATHAN" (Hobbes, 1958: I42). Para Hobbes, aunque la comunidad transfiere la soberanía, se trata de un Estado que tiene que usar la fuerza por el bienestar de todos.

17. Hay quienes han comparado la teoría del Estado de Hobbes con la de San Agustín porque en el siglo IV d.C. el obispo de Hipona, introduciendo elementos teológicos, consideraba al Estado como consecuencia de los malos instintos humanos a partir del pecado original; el Estado era un medio necesario para controlar dichos malos instintos. Tomás de Aquino, en cambio, en el siglo XII veía al Estado como una institución necesaria para el bien común y que sería indispensable aunque el hombre no hubiera pecado.

18. Su posición relativa a la subordinación de la Iglesia al Estado le valió también a Hobbes las críticas de la Iglesia católica. Compartía entonces la doctrina del Erastianismo, proveniente del teólogo protestante suizo Thomas Lieber llamado 
aunque se muestre partidario de la monarquía, la fuerza del rey viene dada por el pacto surgido desde abajo, donde el pueblo le ha transferido realmente determinados derechos.

En Inglaterra la Revolución gloriosa (The Glorious Revolution) de 1688 derrocó a Jacobo II e instauró el modelo de la monarquía parlamentaria inglesa que subsiste hasta hoy. Fue la primera transición del Estado absolutista al liberal, y la gran discusión seguía siendo si el rey tenía poderes divinos para gobernar; polémica que estaba envuelta en una pugna político-militar contra los poderes del parlamento. Este tipo de conflicto ya había ocurrido durante la guerra civil entre el rey Carlos I y Cromwell, ${ }^{19}$ y había terminado con el derrocamiento y decapitación del primero en 1649, si bien luego, con la coronación de Carlos II y la restauración de la monarquía, Inglaterra volvió al modelo absolutista. El derrocamiento de Jacobo II marcó en Europa el inicio de un Estado en que la figura principal del gobierno es el parlamento. Así había terminado el poder absoluto del monarca y este tenía que conformarse con ser una figura importante y tener ciertas funciones de representatividad formal, pero no capacidad para obstaculizar el parlamentarismo, compuesto de varios partidos y representado por un primer ministro.

A partir de la monarquía parlamentaria surgió de manera explícita el concepto liberalismo a través de John Locke (1603-704), especialmente a través de su mejor obra

Erasto, del siglo XVI, quien sostuvo la potestad del Estado sobre el orden religioso, de manera semejante a como lo había hecho también Richard Hooker en Inglaterra con su obra Of the Lawes of Ecclesiastical Politie.

19. Con la ejecución de Carlos I, Cromwell abolió la monarquía en Inglaterra en 1649, pero después de la muerte de Cromwell, Carlos II volvió del exilio y pudo restaurarla en 1660 bajo su propio reinado hasta su muerte en I685.A su sucesor, Jacobo II, le tocaría ser el último soberano absoluto hasta el momento de su derrocamiento en 1688 con la revolución que instauró la monarquía parlamentaria. Carlos II en el momento de su muerte pidió su admisión en la Iglesia católica y Jacobo II se declaró católico, pero fueron los últimos porque en adelante Inglaterra permanecería protestante de manera definitiva. 
Política, democracia y liberalismo en el origen de la época moderna

política, Two Treatises of Government, a la cual se le puede añadir su aportación sobre la libertad religiosa en su obra Letters concerning Toleration. Si buscamos la relación con los principales elementos formulados por los anteriores pensadores, se puede ver que Locke parte también de la naturaleza del ser humano y del principio de soberanía popular, pero enfatiza -a diferencia del estado natural de guerra, de Hobbes- la situación de libertad natural que lleva a los hombres a vivir juntos, según la razón, a través de un pacto, pero reclamando la conservación de los derechos individuales, ${ }^{20}$ la libertad y el bien común en la construcción del Estado. De hecho, tanto la comunidad política como la necesidad de un gobierno tienen un fundamento racional; el estar juntos surge de un consentimiento que tiene como objetivo "la mutua preservación de sus vidas, libertades y patrimonios, que llamamos, de modo general, propiedad" (Locke; citado en Copleston, 1988b: 130).

Ciertamente, también acorde con la razón, hay que crear un gobierno que garantice el orden general para el goce de las libertades, pero, para evitar cualquier tipo de absolutismo por parte de los gobernantes, tienen que crearse contrapesos institucionales. Locke fue el primero en concebir un modelo teórico de Estado ${ }^{21}$ en el cual el poder tiene que

20. Para Locke, dentro de los derechos naturales, el principal de ellos estará en el derecho a la propiedad privada, la cual será uno de los fundamentos materiales del liberalismo." El derecho natural al que Locke dedica más atención es, sin embargo, el derecho de propiedad. Como el hombre tiene el deber y el derecho de la propia conservación, tiene derecho a las cosas que le son necesarias para este fin [...]. En el estado de naturaleza, el hombre trabaja para sí, y hace suyo lo que saca de su estado originario mezclándolo con su trabajo" (Copleston, 1988b: 128). 2l. El nacimiento del Estado moderno es formulado por primera vez por Locke a través de esta división de poderes. Anteriormente se podía mencionar que el Estado era el gobierno, recordando una frase atribuida en forma dudosa por algunos a Luis XIV de Francia: L'État c'est moi, como imagen del Estado absolutista. Sin embargo, la mejor formulación del Estado moderno la realizará posteriormente en el siglo XVIII el Barón de Montesquieu con su mejor obra (De l'Esprit des Lois), al concebirlo como una institución dividida en tres poderes: el ejecutivo, el legislativo y el judicial.

Teoría y DEBATE No. 60 
dividirse entre el poder ejecutivo del gobernante y el poder legislativo del parlamento, donde los individuos deben estar representados. El liberalismo de Locke es el gran símbolo de la transición del absolutismo hacia un modelo de Estado que debe tener contrapesos institucionales y representatividad de los ciudadanos. Hay autores que han conectado necesariamente el liberalismo con la democracia, pero, como bien lo señala Norberto Bobbio, estos conceptos no son interdependientes:

Por liberalismo se entiende una determinada concepción del Estado, la concepción según la cual el Estado tiene poderes y funciones limitados, y como tal se contrapone tanto al Estado absoluto como al Estado que hoy llamamos social [...]. Un Estado liberal no es por fuerza democrático: más aún, históricamente se realiza en sociedades en las cuales la participación en el gobierno está muy restringida, limitada a las clases pudientes. Un gobierno democrático no genera forzosamente un Estado liberal (Bobbio, 1991: 7).

La posibilidad de vincularlos surge de la concepción del legislativo como poder supremo que debe representar a los ciudadanos. Sin embargo, la forma de representación no se da más que por medio de la elección de los legisladores a manos de los ciudadanos organizados que los postulan y los designan mediante el voto. Este tipo de elección brotó en Inglaterra de la fuerza política de la nobleza, y por ello los comicios se desarrollaban con la participación única de sectores calificados, es decir, de los que tuvieran propiedades significativas. El proceso histórico posterior llevó, sin embargo, también a que otros sectores presionaran por tener acceso al parlamento y por ello se formó la cámara de los comunes. En el siglo XIX y XX, los procesos de elección avanzaron hasta el sufragio universal, que tuvo que incluir también a las mujeres y a los jóvenes, algo no contemplado en el origen de la democracia representativa. 
Política, democracia y liberalismo en el origen de la época moderna

A partir de Locke se ha querido formular el modelo de la democracia liberal como ideal para las sociedades modernas; no obstante, por sus escritos, a este autor hay que reconocerle más el concepto liberalismo -un Estado que guarda equilibrio a través de sus contrapesos institucionales entre el ejecutivo y el legislativo- que el de democracia moderna; concepto cuya paternidad moderna se debe a Francisco Suárez, si bien resurgió con un fundamento racional y de manera explícita hasta el holandés Baruch Spinoza (1632-1677).

Spinoza se incluye también necesariamente entre los representantes del racionalismo de la época moderna. Su trabajo sobre la Ethica ordine geometrico demonstrata es un claro ejemplo del método geométrico racional que quiere aplicar a la exposición de su pensamiento, a través de definiciones con ideas claras, postulados enumerados, demostraciones y deducciones lógicas. La aplicación de su pensamiento al ámbito de la ética y de la política tenía que seguir los mismos principios racionales: "Aquellos hombres que están gobernados por la razón, es decir, los hombres que, bajo la guía de la razón, buscan lo que les es útil, nada desean para sí mismos que no deseen también para el resto de la humanidad. Y son, en consecuencia, justos fieles y honorables" (Spinoza; citado en Copleston, 1988b: 234). Spinoza partía también de la ley natural y por ello planteaba que la comunidad política es una necesidad natural y que, al hacer un pacto para formar gobierno, las restricciones que pueda haber a la libertad individual se justifican a partir del bien común o interés colectivo acorde a la razón. Su filosofía política se encuentra en el Tractatus Theologico-Politicus -publicado con un seudónimo años antes de su muerte-, en el Tractatus Politicus ${ }^{22}$ (obra póstuma e incompleta) y en el Tractatus de Deo et Homine eiusque Felicitate.

22. Esta obra fue escrita poco antes de su muerte con el mismo estilo racional aprendido de Descartes. En los cinco primeros capítulos habla sobre la importancia de la política en general como ciencia; luego se refiere en los capítulos 6 y 7 a la

Teoría y DEBATE No. 60 
Spinoza coincidía con Hobbes sobre la existencia de una situación general en que "los hombres son naturalmente enemigos" (Spinoza; citado en Copleston, 1988b: 240). Si cada uno de los seres humanos hiciera su gusto en cualquier momento, no tendríamos en cualquier sociedad más que una situación de anarquía y, por ello, para la conservación de la especie, la misma naturaleza nos llama a la formación de una comunidad política organizada, de un pacto, haciendo de esta manera su interpretación sobre Aristóteles y su animal político: "Todo mundo desea vivir en seguridad y al abrigo de la maldad lo más posible: ahora bien, esta situación es imposible mientras cada cual pueda hacer el bien o el mal a su antojo, porque entonces todos viven con ansiedad en el seno de las enemistades, de la cólera y demás furores semejantes" (Spinoza, 1999: 358). Así pues, el interés racional del bien común justifica la realización de un convenio y las restricciones que se tienen que hacer a los individuos a través del pacto social de mutuo consentimiento. El filósofo holandés retomó el análisis de las tres principales formas de gobierno o dominio sobre la sociedad, la monarquía, la aristocracia y la democracia, señalando con claridad que la mejor es la última.

Cada individuo transfiere su poder a la sociedad, la cual por esto mismo, tendrá sobre todas las cosas el derecho absoluto de la naturaleza, es decir, la soberanía; de suerte que cada uno estará obligado a obedecerla ya de un modo libre, ya por el temor del suplicio. La sociedad en que domina este derecho se llama democracia, la cual puede definirse: asamblea general que posee comunalmente su derecho soberano sobre todo lo que cae en la esfera de su poder (Spinoza, 1999: 360).

forma de gobierno de la monarquía, y en lo capítulos 8,9 y 10 a la aristocracia. Finalmente el capítulo II lo dedica a la democracia como forma de gobierno, que pudo haber sido un gran complemento a lo tratado ya en el Tractatus TheologicoPoliticus. Sin embargo, su muerte en 1677 le impidió finalizar los temas de este libro. 
Política, democracia y liberalismo en el origen de la época moderna

Es en el Tractatus Theologico-Politicus donde hizo estas afirmaciones contundentes, señalando que desde el punto de vista racional la democracia, como poder de la comunidad, es la forma más acorde a los intereses de toda la sociedad: "La república más libre es aquella cuyas leyes se fundan en la sana razón, porque cada cual puede leer en ella ser libre, es decir, seguir en su conducta las leyes de la equidad" (Spinoza, 1999: 361). La teoría de Spinoza se fundamenta también en el mismo pacto social hecho por los seres humanos con el objeto de controlar el poder y la fuerza de sus apetitos; la obligación de vivir y preservar la especie los lleva a vivir en comunidad bajo un soberano que tenga poder para hacer cumplir las leyes de ese pacto, pero cuando dicho soberano es la propia comunidad con poder, tenemos el fundamento racional de la forma democrática de gobierno. Su conclusión fue clara:

Pienso haber demostrado con bastante claridad en qué consisten los fundamentos de la democracia. He preferido tratar de esta forma de gobierno por parecerme la más natural y la más propia a la libertad que la naturaleza da a todos los hombres, porque en este Estado nadie transfiere a otro su derecho natural sino que le cede a favor de la mayoría de la sociedad entera de que es una parte. Por este medio todos vienen a ser iguales como antes en el estado natural (Spinoza, 1999: 361 ).

Spinoza realizó la primera apología moderna de la democracia en el siglo XVII siguiendo las reglas de la razón; los gobernantes no tienen un poder divino sino un sustento popular, y la manera de gobernar debe ser atendiendo a la representación de los ciudadanos: "en una democracia, dice Spinoza, las órdenes irracionales son menos de temer que en cualquier otra forma de constitución" (Copleston, 1992: 242), y citando directamente a Spinoza señala que "es casi imposible que la mayoría de un pueblo, especialmente si

Teoría y DEBATE No. 60 
es una gran mayoría, convenga en un designio irracional. Y, además, la base y la finalidad de una democracia es evitar los deseos irracionales y poner a los hombres en la mayor medida posible bajo el control de la razón, de modo que puedan vivir en paz y armonía" (Spinoza, citado en Copleston, 1992: 242).

\section{Conclusiones}

Al finalizar el siglo XVII se han delineado tres grandes corrientes teóricas que siguen siendo el marco de la discusión de la teoría política contemporánea. Por un lado, se sitúa la posición sobre la soberanía del monarca y su poder indiscutible para establecer e imponer incluso con la fuerza de las armas un orden social determinado, a raíz del pensamiento de Hobbes y, en alguna medida también, de Bodin, quien introduce el rasgo de la tolerancia religiosa. Por otra parte, ha quedado resaltado que el pensamiento democrático tiene una primera expresión en la soberanía popular de Suárez, la cual se expresa también en la teoría federalista de Althusius y de manera expresa en la reaparición del modelo democrático racional de Spinoza, quien "es el primer filósofo que escribió una defensa sistemática de la democracia" (Rosen; en Strauss y Cropsey, 2000: 433), olvidada desde la oración fúnebre de Pericles y la muerte de Sócrates. Con todo, es a Suárez, presente en ese mismo siglo a quien algunos consideran el padre "de la democracia moderna" (Scanone, 1998). Por último, hemos visto que nació con Locke la primera teoría del Estado como separación de poderes y contrapeso entre el ejecutivo y el legislativo, a través del concepto liberalismo, cuyo punto de partida está en la participación ciudadana y en las libertades: "Todo gobierno está limitado en sus poderes y existe sólo por el consentimiento de los gobernados. Y el principio en el 
Política, democracia y liberalismo en el origen de la época moderna

que Locke funda esto es: Todos los hombres nacen libres" (Goldwin; en Strauss y Cropsey, 2000: 451).

En todas estas corrientes, por otro lado, ha surgido también el estudio sistemático de la política con sus leyes propias -independiente de los designios divinos-, donde se propone que debe imperar el sentido de lo colectivo y los intereses comunes sobre los particulares; por ello, en este trabajo se ha resaltado especialmente la obra de Althusius, porque significa el inicio del estudio de la política como un objeto específico en el campo de las disciplinas académicas reconocidas, y porque, al mismo tiempo, nos introduce a la propuesta de un modelo de democracia social cuando señala la necesidad de que el gobierno implemente una manera de compartir las cosas materiales y los saberes en un sistema regido por leyes e inserto en una federación de comunidades.

Los pensadores tratados son la antesala de todo el fenómeno de la Ilustración europea del siglo XVIII, la cual será necesariamente el contexto del acontecimiento que marcará con más claridad la ruptura con el Estado absolutista cuando una nueva cultura política penetró en el espíritu de los ciudadanos, llevándolos a participar tanto en las elecciones de los gobernantes como en las decisiones del Estado. Los planteamientos de los primeros teóricos de la política moderna deben ser retomados y reinterpretados como marco de discusión para la consolidación de nuestras sociedades contemporáneas.

Fecha de recepción: 27de junio de 2012

Fecha de aceptacion: 09 de abril de 2014

Teoría y DEBATE $\&$ No. 60 
Ignacio Medina Núñez

Bibliografía
Althusius, Johannes, 1964, Politics Methodically Set Forth, and Illustrated with Sacred and Profane Examples. The Politics of Johnnes Althusius, Beacon Press, Boston, en línea: http:// www.constitution.org/alth/alth.htm
Bachelard, Gaston, 1994, La tierra y los ensueños de la voluntad, Fondo de Cultura Económica, México.

Barbier, René, 2007, Histoire du concept d'Imaginaire et de ses transversalités, Université de Paris VIII, París, en línea: www.barbier-rd.nom.fr/Histoiredimaginaire.htm

Beck, Ulrich, 2007, Dialektiken der Moderne: Wie die Krisen der Moderne aus den Siegen der Moderne hervorgehen, Madrid, UNED, en línea: http://portal.uned.es/pls/portal/docs/

Bloch, Ernst, 1972, La Philosphie de la Renaissance, Petite Bibliotèque Payot, Francia.

Bobbio, Norberto, I99I, Liberalismo y Democracia, Fondo de Cultura Económica, México.

Bosca, Roberto, 2008, “Ley, guerra y paz en Francisco Suárez”, en Terceras Jornadas Internacionales: De lustitia et lure en el Siglo de Oro (2-4 de junio), Universidad Católica Argentina/Universidad de Navarra, Buenos Aires.

Copleston, Frederick, I 988a, Historia de la Filosofia.Vol. III:De Ockham a Suárez, Ariel, México. , I 988b, Historia de la Filosofia.Vol. v. De Hobbes a Hume, Ariel, México.

, 1 992, Historia de la Filosofía.Vol. Iv. De Descartes a Leibniz, Ariel, México.

Domínguez, Atilano, 20I I, Libertad y Democracia en la filosofia política de Spinoza, en línea: http://filosofiasocial. wordpress.com/

Duso, Giuseppe, 2005, El poder. Para una historia de la filosofía política moderna, Siglo XXI, México.

Echeverría,Javier (ed.), 2000, Del Renacimiento a la llustración, Trotta, Madrid. 
Política, democracia y liberalismo en el origen de la época moderna

Elazar, Daniel J., 2010,Althusius and Federalism as Grand Design, Bibliografía Jerusalem Center for Public Affairs, Jerusalén, en línea: http://www.jcpa.org/dje/articles2/althus-fed.htm

Habermas, Jürgen, I 989, El discurso filosófico de la modernidad, Altea/Taurus/Alfaguara, Madrid.

Hirschberger, Johannes, 1988, Breve historia de la filosofia, Herder, Barcelona.

Hobbes, Thomas, 1958, Leviathan. Parts I and II (Introducción de Herbert W. Schneider), The Liberal Arts Press, Inc., Estados Unidos. 1994, Leviatán o la materia, forma y poder de una república eclesiástica y civil, Fondo de Cultura Económica, México.

Hueglin, Thomas O., 1999, Early modern concepts for a late modern world: Althusius on community and federalism, Wilfrid Laurier University Press, Ontario, Canadá.

Huesbe Llanos, Marcos A., 1999, "Reforma política luterana en el siglo XVII. De Martín Lutero a Henning Arnisaeus”, Revista de Estudios Histórico-Jurídicos, vol. 21 , pp. 255-336.

Lander, Edgardo (ed.), I99I, Modernismo \& Universalismo. Pensamiento crítico: un diálogo interregional I, Editorial Nueva Sociedad/UNESCO/Universidad Central de Venezuela, Caracas, Venezuela.

Marius, Richard, 1999, Martin Luther. The Christian between God and death,The Belknap press of Harvard University Press, Cambridge, MA/Londres.

Maquiavelo, Nicolás, 2000, Discursos sobre la primera década de Tito Livio, Alianza Editorial, Madrid.

Mattelart, Armand, 2000, Historia de la utopía planetaria. De la ciudad profética a la sociedad global, Paidós, Barcelona. Merriman, John, 1996, A history of Modern Europe. Volume one. From the Renaissance to the Age of Napoleon, W.W Norton \& Company, Londres/Nueva York.

Montesquieu, 2003, Considérations sur les causes de la grandeur des Romains et de leur decadence (Documento elaborado 
Ignacio Medina Núñez

Bibliografía

por Ugo Bratelli. Edición digital a partir del texto de Montesquieu [172I] por Garnier-Flammarion [1968]), Quebec, Chicoutimi.

Pirenne, Henri, 1995, Historia de Europa. Desde las invasiones al siglo XVI, Fondo de Cultura Económica, México.

Ranke, Leopold von, 2000, Historia de los papas, Fondo de Cultura Económica, México.

Rodríguez Paniagua, José María, 1983,“El pensamiento filosófico político de Baruch Spinoza”, Revista de Estudios Políticos (nueva época), núm, 36, pp. I59-180.

Sabine, George H., 2000, Historia de la teoría política (Edición revisada por Thomas Landon Thorson), Fondo de Cultura Económica, México.

Salamone Savona, María Antonieta, 20 I I,"Desde el republicanismo clásico hasta el contractualismo moderno: el De Principatu de M. Salamone y el Principatus Politicus de F. Suárez", INGENIUM, Revista de historia del pensamiento moderno, núm. 5, pp. 189-207.

Scanone, Juan Carlos, 1998, “Lo social y lo político, según Francisco Suárez”, Xipe Totek, Revista de Filosofia y Ciencias Sociales, vol. VII, núm. 2, pp. I3I-I7I.

Spinoza, 1999, Ética. Tratado Teológico-Político, Porrúa, México. , 1998, Benedict de Spinoza's Politica Treatise. Tractatus Politicus (Edición e introducción de R.H. M. Elwes; edición digital de Constitution Society), Londres, en línea: http://www.constitution.org/bs/poltr-00.htm Strauss, Leo y Cropsey, Joseph (comps.), 2000, Historia de la Filosofia Política, Fondo de Cultura Económica, México. Universidad Nacional Autónoma de México, 1988, La sociedad a través de los clásicos (Cuadernos de Extensión Académica), UNAM, México. 